\title{
ESBOZO DE UN MODELO DE ATRIBUCIÓN DE RESPONSABILIDAD PENAL DE LAS PERSONAS JURÍDICAS
}

\author{
Outline of a model for attributing legal persons 'criminal liability
}

Percy García Cavero*

\begin{abstract}
Resumen: El artículo ofrece una panorámica general sobre los dos modelos de imputación de responsabilidad penal a las personas jurídicas, a saber, el modelo de responsabilidad penal por el hecho de otro, consistente en imputar a la persona jurídica la responsabilidad por el injusto penal que realizan sus órganos o representantes; y el modelo de responsabilidad por hecho propio que, como su nombre indica, sustenta la responsabilidad penal de la persona jurídica en un hecho de la propia persona jurídica. Luego plantea un breve esbozo de una propuesta al respecto, sobre la base de un modelo de imputación de responsabilidad penal a las personas jurídicas por hecho propio. Señala que la culpabilidad de la persona jurídica solamente puede establecerse mediante un concepto de culpabilidad análogo. El injusto imputable se funda en una organización defectuosa y la persona jurídica, en tanto titular de una esfera de organización propia, puede ser hecha directamente responsable por los defectos de configuración negativos o positivos de su esfera de organización. Por último, el trabajo analiza el modelo asumido por el derecho penal chileno, mediante la dictación de la Ley $\mathrm{N}^{\circ} 20.393$ (D.O. 02.12.2009), que establece la responsabilidad penal de las personas jurídicas solamente en el caso de los delitos de lavado de activos, financiamiento del terrorismo y cohecho.
\end{abstract}

Palabras clave: modelos de imputación de responsabilidad penal - responsabilidad penal de las personas jurídicas - culpabilidad - Ley $\mathrm{N}^{\circ} 20.393$.

\begin{abstract}
The article provides an overview of the two models for attributing legal persons'criminal liability. One of the models attributes criminal liability for acts committed by a third party, where the legal person is made responsible for the criminal actions performed by the legal person's organs or representatives. The second model, commonly referred to as responsibility for one's own actions, which as its name suggests, attributes criminal liability directly to the legal person for his/her own actions. Then, it presents a brief outline of a proposal in this regard, on the basis of a model attributing criminal liability to legal persons for his/her own actions. It notes that the culpability of the legal person can only be established through an analogous concept of culpability. The attributable wrongdoing consists on a defective organization and the legal person, as a holder of a sphere of self-organization, may be made directly responsible for the design flaws of their negative or positive organizational sphere. Finally, the paper analyzes the model assumed by the Chilean criminal law through the enactment of Law $\mathrm{N}^{\circ} 20.393$ (D.O. 12.2.2009), which imposes criminal liability of legal persons only for the offenses of money laundering, terrorist financing and bribery.
\end{abstract}

Keywords: attribution models of criminal liability - criminal liability of legal persons culpability - Law No 20.393.

\footnotetext{
* Abogado, Doctor en Derecho Universidad de Navarra, Catedrático de Derecho Penal de la Universidad de Piura (Perú). Correo electrónico: percy.garcia@udep.pe
} 
García - Esbozo de un modelo de atribución de responsabilidad penal...

\section{Introducción}

Es un dato incontrastable que los contactos sociales cuentan en la actualidad con una intervención preponderante de las personas jurídicas. En el terreno de la economía, la empresa ha desplazado claramente a la figura del comerciante individual como sujeto de las operaciones y transacciones económicas. ${ }^{1}$ Esta situación ha traído como consecuencia no sólo que la regulación jurídico-privada se oriente desde hace ya buen tiempo hacia el fenómeno corporativo, sino también que el propio sistema penal empiece a plantearse la necesidad legislativa de considerar a la persona jurídica en sus criterios de imputación de responsabilidad. El punto de partida, en el que conviene unánimemente la doctrina penal, es que la atribución de responsabilidad penal por los delitos cometidos en el marco de la actividad de una persona jurídica no puede limitarse únicamente a sujetos individuales. Consideraciones de carácter político-criminal ponen de manifiesto que la pena a los miembros de la empresa resulta insuficiente en términos de prevención o mantenimiento de la vigencia del orden normativo, por lo que el Derecho Penal debe incorporar medidas aplicables directamente a la empresa misma. ${ }^{2}$

Manteniéndose en el postulado clásico de que las personas jurídicas no tienen capacidad delictiva, diversas legislaciones penales prevén actualmente la posibilidad de que el juez penal pueda imponer, en el marco de un proceso penal, medidas específicas a las personas jurídicas con la finalidad de impedir la comisión de nuevos delitos. Se trata de una tercera forma de reacción penal a la que se le ha denominado consecuencias accesorias, cuya naturaleza penal o administrativa se discute doctrinalmente, pero a las que, en todo caso, se les niega el carácter de

\footnotetext{
${ }^{1}$ Vid. García Cavero, Percy: Derecho penal económico, 2007, p. 651.

${ }^{2} \mathrm{La}$ insuficiencia de las sanciones penales impuestas a los sujetos individuales para hacer frente a la criminalidad desde la empresa se evidencia fundamentalmente a partir de ciertos datos criminológicos. Por un lado, se ha llegado a determinar con una base empírica comprobada cómo la cultura corporativa de una empresa puede tornarse en criminógena, es decir, fomentar que los miembros materialicen hechos delictivos en cumplimiento de las directrices de conducta que la empresa desarrolla a su interior [vid., con mayor detalle, Schünemann, Bernd: Unternehmenskriminalität und Strafrecht, 1979, p. 22 ss.; Lampe, Ernst-Joachim: La dogmática jurídico-penal entre la ontología social y el funcionalismo, 2003, pp. 130 ss.; Dannecker, Gerhard: Zur Notwendigkeit der Einführung kriminalrechtlicher Sanktionen gegen Verbände, 2001, p. 108; Zúñiga Rodríguez, Laura: Bases para un modelo de imputación de responsabilidad penal a las personas jurídicas, 2003, p. 240]. De este modo, sancionar únicamente a los miembros individuales de la empresa no erradicaría la cultura corporativa criminógena y, por tanto, el peligro de la futura comisión de hechos delictivos. En segundo lugar, se ha demostrado también que la empresa moderna recurre con mayor frecuencia a la figura de los directivos de banquillo, es decir, personas incorporadas a la estructura empresarial con la única finalidad de asumir plenamente la responsabilidad penal por los hechos delictivos cometidos desde la empresa [Vid., Seelmann, Kurt: "Punibilidad de la empresa", en García Cavero, Percy (coord.), La responsabilidad penal de las personas jurídicas, órganos y representantes, 2004, p. 32]. En este sentido, las sanciones penales perderían completamente su virtualidad preventiva si la sanción se quedase en el directivo individual, pues la empresa se limitaría sólo a contabilizar el costo de un director de banquillo frente a los beneficios que le proporcionaría el desarrollo de la actividad ilícita.
} 
penas. Dado que las personas jurídicas no pueden cometer un injusto culpable que justifique algún tipo de medida restrictiva de derechos, las legislaciones penales que admiten las llamadas consecuencias accesorias necesitan encontrar algún fundamento con el cual legitimar su imposición. Con una que otra matización, este fundamento se procura alcanzar con la existencia de una peligrosidad objetiva de la organización de la persona jurídica, lo que significa recurrir a un enfoque prospectivo en relación con la protección futura de bienes jurídicos. ${ }^{3}$

Pese a que el sistema de consecuencias accesorias parecería cubrir la necesidad político-criminal de actuar directamente sobre la persona jurídica, el hecho es que tampoco resulta plenamente satisfactorio de cara a la función atribuida al Derecho Penal. Por un lado, el fundamento prospectivo de las consecuencias accesorias hace inviable la imposición o continuación de dichas medidas si es que se excluye o reduce la peligrosidad futura de la organización. Pero, por otro lado, su carácter accesorio en relación con la responsabilidad penal de una persona individual provoca ciertas limitaciones si es que no hay un autor individual responsable. Por estas razones, cobra mucha fuerza la necesidad de imponer sanciones penales a la propia persona jurídica, lo que ha llevado a una proliferación de planteamientos sobre la posibilidad de construir una culpabilidad jurídico-penal de las personas jurídicas. Incluso muchos autores que le niegan a la persona jurídica una culpabilidad jurídico-penal en sentido estricto, convienen en la necesidad de imponerle una pena y, por lo tanto, en el reconocimiento de una forma especial de responsabilidad penal. ${ }^{4}$

El hecho es que, sea por la vía de una culpabilidad penal de las personas jurídicas o por la vía de otros criterios de fundamentación, la responsabilidad penal de las personas jurídicas ha comenzado su marcha triunfal en la legislación penal de diversos países de tradición europeo-continental. Sin embargo, debe reconocerse que esta nueva configuración de los criterios de imputación penal no se ha debido a las exigencias de una dogmática convencida en la capacidad delictiva de las personas jurídicas, sino que se ha dado a raíz de la política unificadora de los mercados y la economía. Así, es conocido que en Europa la

\footnotetext{
3 Vid., con mayores referencias, García Cavero, Percy: Derecho penal económico (nota 1), p. 968 ss.

${ }^{4}$ Así, por ejemplo, es el caso del planteamiento de Schünemann, Bernd: Responsabilidad penal de la empresa y sus órganos directivos en la Unión Europea, 2006, pp. 10 ss., quien recurre al llamado estado de necesidad preventivo de bienes jurídicos, lo que hace que el fundamento de las sanciones penales a las personas jurídicas termine siendo el mismo criterio preventivo que legitima la imposición de medidas de seguridad a las personas físicas [Schünemann, Bernd: "La punibilidad de las personas jurídicas”, en AA.VV., Hacia un Derecho penal económico europeo, 1995, p. 590]. También puede mencionarse aquí la propuesta de Alwart de un modelo subsidiario de responsabilidad penal de las empresas que se fundamentaría no en la culpabilidad de la persona jurídica, sino en un fracaso de la imposición de la pena a los sujetos individuales debido a la organización de la empresa [vid., con mayores indicaciones, Alwart, Heiner: "Strafrechtliche Haftung des Unternehmens - vom Unternehmenstäter zum Tätersunternehmen”, ZStW 105, 1993, pp. 759 ss., 769 ss.; Alwart, Heiner: Zurechnen und Verurteilen, 1998, pp. 28 ss.; Alwart, Heiner: "Unternehmensethik durch Sanktion?", en del mismo Verantwortung und Steuerung von Unternehmen in der Marktwirtschaft, 1998, pp. 75 ss.].
} 
García - Esbozo de un modelo de atribución de responsabilidad penal...

progresiva introducción de una responsabilidad de las personas jurídicas respondió a la directiva que en 1988 dio la Comunidad Europea a los Estados miembros para implantar sanciones directas a las personas jurídicas con la finalidad de proteger de esta manera las condiciones del mercado común. ${ }^{5}$ En el caso de Chile es un hecho incuestionable que la incorporación de la responsabilidad penal de las personas jurídicas se ha hecho para cumplir con ciertos requisitos para poder acceder a la OCDE. ${ }^{6}$ Esta tendencia legislativa complaciente con una responsabilidad penal de las personas jurídicas se ha visto reforzada además por los acuerdos internacionales de lucha contra la criminalidad transnacional, en donde se recomienda a los países parte incorporar sanciones penales a los entes colectivos (por ejemplo, la Convención de Palermo de 2000).

En este contexto, más político que jurídico, los cambios se han producido rápidamente en el plano legislativo, mientras que en la discusión doctrinal las opiniones siguen estando encontradas no sólo en la cuestión del "sí" de la responsabilidad penal de las personas jurídicas, sino fundamentalmente del "cómo" se debe imputar responsabilidad a los entes colectivos. Está claro que la incorporación legislativa de medidas aplicables directamente a las personas jurídicas requiere no sólo de una decisión política, sino también de una fundamentación dogmática. Al respecto, Bacigalupo Zapater ha destacado que "el fundamento de estas legislaciones sigue siendo poco seguro". " Si bien podría seguirse la afirmación contenida en la exposición de motivos del legislador suizo que incorporó la responsabilidad penal de las personas jurídicas, en el sentido de que "finalmente no es la dogmática, sino la voluntad del legislador de regular convenientemente una situación problemática la que decide si esta regulación resulta permitida", ${ }^{8}$ esta oposición de "lo conveniente" con "lo dogmático" hace que se rompa el necesario juego en equipo entre ambos, lo que lleva finalmente a que el Derecho no pueda enseñarse, aprenderse, controlarse y aplicarse.

Por lo anterior, queda completamente claro que no basta con el reconocimiento legal de una responsabilidad penal de las personas jurídicas, sino

\footnotetext{
${ }^{5}$ Vid., Achenbach, Hans: "Sanciones con las que se pueden castigar a las empresas", en Silva Sánchez, Jesús María (dro.), Fundamentos de un sistema europeo de Derecho penal, 1995, pp. 381 ss.; Pedrazzi /Alessandri/Foffani/Seminara/Spagnolo: Manuale di diritto penale dell'impresa, 2000, pp. 82 ss.; Bacigalupo, Silvina: La responsabilidad penal de las personas jurídicas, 2001, pp. 141 ss.; Bajo Fernández, Miguel: "La responsabilidad de las personas jurídicas", en CDJ: La responsabilidad penal de las sociedades, actuación en nombre de otro, responsabilidad de los consejos de administración, responsabilidad de los subordinados, 1994, p. 103; Silva Sánchez, Jesús María: "La responsabilidad penal de la empresa", en del mismo, Fundamentos de un sistema europeo del Derecho penal, 1995, p. 358; Zugaldía Espinar, José Miguel: "Capacidad de acción y capacidad de culpabilidad de las personas jurídicas", CPC, 1994, p. 617.

${ }^{6}$ Vid., con mayores detalles, Hernández Basualto, Héctor: "La introducción de la responsabilidad penal de las personas jurídicas en Chile”, Política criminal, 2010, p. 208 ss.

7 Bacigalupo, Enrique: "Las teorías de la pena y el sujeto del Derecho penal", en Yacobucci, Guillermo (dr.), Los desafios del Derecho penal en el siglo XXI, 2005, p. 188.

${ }^{8}$ Citado por Seelmann, Kurt: Punibilidad de la empresa (nota 2), p. 25.

${ }^{9}$ Ibid., p. 26.
} 
que la dogmática penal debe, antes o después de la reforma legal, proveer de los insumos dogmáticos necesarios para sustentar la imposición de una sanción penal a las personas jurídicas. Si no se trabaja en la legitimación jurídica de estas medidas, se habrá vuelto a la época en la que Administración de Justicia se realizaba de manera arbitraria, con absoluta carencia de razones justificadas para intervenir sobre los ciudadanos. Una decisión correcta solamente podrá alcanzarse de forma intuitiva. Por estas razones, me ocuparé, en lo que sigue, de hacer, luego de una panorámica general sobre los distintos modelos de atribución de responsabilidad a las personas jurídicas, un breve esbozo de una propuesta personal al respecto, con cuya ayuda podré ofrecer algunas pautas interpretativas sobre cómo la legislación penal chilena podría regular la responsabilidad penal de las personas jurídicas.

\section{Los modelos de atribución de responsabilidad penal a las personas jurídicas}

\section{a) El modelo de responsabilidad penal por atribución del hecho de otro}

La forma de atribuir responsabilidad penal a las personas jurídicas puede seguir diversos modelos. Posiblemente el más elemental sea el modelo de responsabilidad penal por atribución, ${ }^{10}$ el cual consiste en transferir a la persona jurídica la responsabilidad penal por el injusto penal que realizan sus órganos o representantes. Este modelo se corresponde con la teoría de la identificación o alter ego theory de procedencia anglosajona. ${ }^{11}$ La principal labor de fundamentación dogmática que precisa este modelo de atribución de responsabilidad penal reside en el título por el cual la responsabilidad penal por el hecho puede ser transferida del sujeto individual a la persona jurídica. ${ }^{12}$ En un plano más operativo, este modelo debe determinar también cuándo tiene lugar el llamado elemento de conexión entre la actuación del órgano o representante y la persona jurídica.

El modelo de la atribución del hecho de otro es sometido a diversas críticas que ponen en tela de juicio su viabilidad dogmática. Si bien este modelo

\footnotetext{
${ }^{10}$ Críticamente con la terminología, Gómez-Jara, Carlos: La culpabilidad penal de la empresa, 2005, p. 140, pues entiende que todo modelo de responsabilidad penal de las personas jurídicas se sustenta en un acto normativo de atribución de dicha responsabilidad.

${ }^{11}$ La teoría del alter ego tuvo su origen en Inglaterra por el juez Haldane (1915). Esta teoría está siendo actualmente cuestionada desde estudios procedentes del mismo ámbito angloamericano, en el sentido de la necesidad de fundamentar la responsabilidad de las personas jurídicas en un defecto propio de organización, esto es, en una culpabilidad propia de la persona jurídica [vid., las referencias bibliográficas en Kremnitzer, Mordechai/Ghanayim, Khalid: "Die Strafbarkeit von Unternehmen", ZStW 113, 2001, p. 560, nota 89].

12 Así, lo destaca, Silva Sánchez, Jesús María: "La responsabilidad penal de las personas jurídicas", en García Cavero, Percy (coord.), La responsabilidad penal de las personas jurídicas, órganos y representantes, 2004, p. 115.
} 
García - Esbozo de un modelo de atribución de responsabilidad penal...

conlleva una transferencia de la responsabilidad penal, esta transferencia no puede alcanzar lo subjetivo, pues lo interno del órgano no se puede transferir a la persona jurídica. En consecuencia, este modelo de atribución se sustentaría, en el fondo, en una pura responsabilidad objetiva de la persona jurídica, lo que difícilmente resulta compatible con una imputación penal regida por el principio de culpabilidad por el hecho propio. ${ }^{13}$ Por otra parte, se le ha reprochado llevar a cabo una doble valoración del hecho para sustentar la imputación al representante y a la persona jurídica. El representante de la persona jurídica actuó como tal o como persona individual, pero lo que no es posible es que haya actuado en ambos roles al mismo tiempo. ${ }^{14}$ Por lo tanto, o responde el representante por su hecho, o responde la persona jurídica por el hecho de su representante, pero no ambas cosas. Dado que ningún sistema penal está dispuesto a renunciar a la pena del representante, la tendencia apunta $a$ ir abandonando los modelos de responsabilidad penal de las personas jurídicas que se sustentan en la atribución del injusto realizado por el órgano o representante.

Con independencia de los cuestionamientos generales al modelo de atribución del hecho ajeno, existen ciertos aspectos discutidos en su propia configuración que determinan el alcance de este modelo. En primer lugar, resulta necesario precisar cuándo se entiende que el agente actúa propiamente como órgano o representante de la persona jurídica. Es posible manejar al respecto fundamentalmente dos interpretaciones: la teoría de la función y la teoría del interés. Conforme a la primera, los representantes u órganos de administración de una persona jurídica solamente actúan como tales si se mueven en el marco de las facultades de representación o administración conferidas, mientras que la segunda teoría sostiene que el representante u órgano de administración sólo actuará como tal si se mueve en el círculo de tareas derivado de su relación de representación, pero siempre en interés de su representada. ${ }^{15}$ En segundo lugar, deben determinarse las exigencias que debe reunir el hecho de conexión del órgano o representante para dar pie a una responsabilidad penal de la persona jurídica. En este punto se discute, por ejemplo, si basta con la realización de un injusto penal por parte del representante o si es necesario también que éste haya actuado culpablemente. Además de la discusión sobre la calidad del hecho de conexión, se suscitan también aspectos de orden procesal, en el sentido de si el hecho de conexión requiere de una individualización y efectiva condena del representante o basta simplemente con tener por acreditado que algún miembro ha cometido un delito en el marco de las actividades de la persona jurídica.

\footnotetext{
${ }^{13}$ En este sentido, ibid., p. 121.

14 Así, Jakobs, Günther: “¿Punibilidad de las personas jurídicas?”, en García Cavero, Percy (coord.), La responsabilidad penal de las personas jurídicas, órganos y representantes, 2004, p. 59: "Si la persona jurídica tiene que reconocer jurídicamente como culpa propia la culpa del órgano, entonces esta culpa es su propia culpa, y ya no cabe hablar de un resto de culpa individual".

15 Sobre la disputa entre la teoría de la función y del interés para determinar cuándo el órgano de una persona jurídica actúa como tal en el marco del actuar en lugar de otro, vid., con mayores referencias, García Cavero, Percy: Derecho penal económico (nota 1), pp. 751 ss.
} 


\section{b) El modelo de responsabilidad por hecho propio}

Como su mismo nombre lo dice, el modelo de responsabilidad por hecho propio sustenta la responsabilidad penal de la persona jurídica en un hecho de la propia persona jurídica. Posiblemente la formulación doctrinal que inicia esta línea de argumentación es la llamada "culpabilidad por defecto de organización" (Organisationsverschulden), formulada originariamente en el ámbito de las contravenciones por Tiedemann y que pone como punto de referencia de la culpabilidad de la persona jurídica a su organización. ${ }^{16}$ Esta culpabilidad radicaría esencialmente en una carencia o deficiencia organizativa de la propia persona jurídica. Por lo tanto, el trabajo dogmático en este modelo apunta fundamentalmente a precisar cuáles son los requisitos necesarios para atribuir a la persona jurídica una defectuosa organización.

La defectuosa organización tiene lugar cuando la persona jurídica ha omitido tomar las medidas de seguridad necesarias para asegurar un funcionamiento empresarial no delictivo, por lo que los hechos individuales de sus órganos o representantes se considerarán delitos de la persona jurídica. Para evitar que esta referencia al hecho del órgano o representante lleve de vuelta al modelo de la responsabilidad por el hecho de otro, se acude a la figura de la omisión y la actio libera in causa con la finalidad de mantener la imputación en la propia persona jurídica. ${ }^{17}$ De esta manera, la responsabilidad de la persona jurídica por los hechos cometidos por sus órganos o representantes se sustentaría en una omisión de medidas de seguridad que ha puesto previamente a la persona jurídica en incapacidad de poder impedir dichos delitos.

A la propuesta de la culpabilidad por defecto de organización se le ha cuestionado no seguir, en realidad, un modelo de autorresponsabilidad, sino mantenerse en un modelo de atribución del hecho de otro. De manera general, se ha dicho que la defectuosa organización es finalmente consecuencia de la actuación indebida de los órganos de control o supervisión a la empresa, por lo que se seguiría trabajando con un modelo de transferencia de la responsabilidad penal. ${ }^{18}$ Este cuestionamiento presupone, sin embargo, que sea posible reconducir la forma de organización de la persona jurídica completamente a la decisión de un órgano de control o supervisión, lo que parece poco plausible, al menos, en organizaciones con cierto grado de complejidad. Por esta razón, no parece razonable calificar, en general, a la culpabilidad por defecto de organización como un modelo de atribución de hecho de otro. Sin embargo, no puede desconocerse que mantiene muchos rasgos de heterorresponsabilidad, como lo sería la necesidad de un hecho de conexión realizado por el órgano o representante, pero

\footnotetext{
16 Vid., Tiedemann, Klaus: Die "Bebußung” von Unternebmen nach dem 2. Gesetz zur Bekämpfung der Wirtschaftskriminalität, NJW, 1988, pp. 1169 ss.

${ }^{17}$ Ibid., p. 1172.

18 Así, Silva Sánchez, Jesús María: La responsabilidad penal de las personas jurídicas (nota 12), p. 119.
} 
García - Esbozo de un modelo de atribución de responsabilidad penal...

sobre todo la negación de supuestos de exculpación en relación con la culpabilidad propia de la persona jurídica. ${ }^{19}$

Un intento de desligar conceptualmente la responsabilidad penal de las personas jurídicas del hecho de conexión individual es, sin duda, la propuesta de una culpabilidad por el carácter de la empresa formulada por Lampe. Según su planteamiento, la culpabilidad de la empresa se sustentaría en haber creado, favorecido o mantenido una filosofía criminógena o ciertas deficiencias organizativas. $^{20}$ Pero cómo se estructura esta culpabilidad, dependerá evidentemente del contenido del injusto en cuanto culpabilidad realizada. En este aspecto, Lampe es muy claro al señalar que la responsabilidad de las empresas económicas no puede apoyarse en el injusto de acción ajeno, sino en el injusto del sistema propio. ${ }^{21}$

La determinación del injusto propio de la empresa precisa de una distinción de los sistemas de injusto jurídico-penales, los que se definen como las relaciones entre individuos organizadas hacia fines injustos. ${ }^{22}$ Estos sistemas pueden ser simples, como lo es la coautoría, o constituidos, como es el caso de las empresas con tendencia criminal, las organizaciones criminales y los Estados criminalmente pervertidos. Lo característico de cada sistema de injusto es su injusto del sistema. ${ }^{23}$ En el caso de la actuación de las personas individuales, el injusto jurídico-penal (injusto personal) es un injusto de relación cuyos componentes son el injusto de la acción y el injusto del resultado. En el caso de las empresas con tendencia criminal, el injusto del sistema estará constituido, más bien, por aquellas formas de comportamiento que lesionan bienes jurídicos y que, o concuerdan con la filosofía de la empresa, o son favorecidas por su organización. ${ }^{24}$ Pese a la independencia conceptual de ambas clases de injusto, Lampe señala, estableciendo un paralelo con la imprudencia leve, que el injusto del sistema de la empresa no es suficiente para generar responsabilidad penal, por lo que resulta necesario que su filosofía criminógena o su deficiencia organizativa se realice a través del injusto personal de un miembro de la empresa que infrinja la norma. ${ }^{25}$ No obstante, debe quedar claro que la actuación del miembro de la empresa no es un hecho de conexión que vuelva al modelo de la atribución de un hecho ajeno, sino que el injusto propio de la empresa se relaciona con un injusto de resultado del miembro individual de la empresa. ${ }^{26}$ Esta relación tiene lugar en términos de elevación del riesgo.

\footnotetext{
${ }^{19}$ Así, Gómez-Jara, Carlos: La culpabilidad penal de la empresa (nota 10), pp. 153 ss.

${ }^{20}$ Vid., Lampe, Ernst-Joachim: La dogmática jurídico-penal (nota 2), p. 162.

${ }^{21}$ Ibid., p. 161.

22 Ibid., p. 103.

${ }^{23}$ Ibid., p. 123.

${ }^{24}$ Ibid., p. 131.

25 Ibid., p. 161.

${ }^{26}$ Así, Gómez-Jara, Carlos: La culpabilidad penal de la empresa (nota 10), pp. 186 ss.
} 
No hay duda de que el planteamiento de Lampe presenta un modelo que construye la responsabilidad penal de la empresa en la atribución de un injusto propio. No obstante, no termina de desvincularse del injusto personal del miembro de la empresa que realiza la conducta antinormativa, aunque solamente se considere como un injusto de resultado del injusto propio de la empresa. Si bien la filosofía criminógena o el defecto de organización elevan el riesgo de un resultado antinormativo realizado personalmente por un miembro de la empresa, la decisión sobre la producción del resultado sigue en manos del miembro individual, lo que hace discutible la imputación del resultado al injusto del sistema de la empresa. Por otro lado, la adhesión de la culpabilidad de la empresa a la culpabilidad por el carácter levanta las críticas que la doctrina penal de manera casi uniforme le asesta a dicha comprensión de la culpabilidad, en el sentido de su falta de correspondencia con una culpabilidad por el hecho. En palabras de Gómez-Jara, "(e)l concepto de culpabilidad por el carácter (empresarial), en definitiva, peca de no poder integrarse en el Derecho penal moderno". ${ }^{27}$

El mismo cuestionamiento de abandonar la culpabilidad penal por el hecho se le puede hacer al planteamiento de Heine que apunta a construir un concepto de culpabilidad empresarial que sea análogo-funcional al Derecho penal individual. Conforme a dicho planteamiento, a la empresa se le asigna el deber de administrar adecuadamente los riesgos (Risikomanagement), por lo que su responsabilidad penal se deriva de una defectuosa administración de los riesgos que, a través de una elevación del riesgo específico, lleva a la realización externa de un riesgo típico de la empresa. ${ }^{28}$ Esta estructuración de la imputación tiene como aspecto resaltable una visión del injusto centrada en la organización (defectuosa) de los riesgos, ${ }^{29}$ pero construye la culpabilidad de la empresa en atención no al hecho defectuoso concretamente realizado, sino a la conducción de la actividad empresarial. ${ }^{30}$ Está claro que lo que se busca es desvincular la culpabilidad empresarial de una decisión concreta tomada por una persona natural en determinado momento, pero, al darle a la dimensión temporal un carácter constitutivo de la culpabilidad empresarial, se desmarca de la culpabilidad por el hecho y entra en el ámbito de la tan cuestionada culpabilidad de autor.

En la actualidad cabe destacar la propuesta de Gómez-Jara Díez, quien emprende el reto de elaborar una teoría del concepto jurídico-penal de culpabilidad que resulte adecuada para personas físicas y jurídicas (empresas). Con base en la teoría de los sistemas y el constructivismo operativo, propone un cambio de paradigma de la imputación penal que deje de lado la visión antropológica de la persona y se centre en la comunicación como elemento

\footnotetext{
${ }^{27}$ Ibid, p. 184.

28 Vid., Heine, Günther: Die strafrechtliche Verantwortlichkeit von Unternebmen, 1995, pp. 292 ss.

${ }^{29}$ Así lo destaca especialmente Gómez-Jara, Carlos: La culpabilidad penal de la empresa (nota 10), pp. 188 ss.

30 Heine, Günther: "Plädoyer für ein Verbandsstrafrecht als zweite Spur”, en Alwart (Hrsg.), Individuelle Verantwortung und Steuerung von Unternebmen in der Marktwirtschaft, 1998, p. 104.
} 
García - Esbozo de un modelo de atribución de responsabilidad penal...

esencial de los sistemas sociales (autopoiéticos). ${ }^{31}$ Como puede verse, este planteamiento hace fructíferas muchas de las ideas desarrolladas por Lampe y Heine, pero no para elaborar una culpabilidad jurídico-penal de la empresa, sino una culpabilidad jurídico-penal en general. Centrado en la función de prevención especial positiva, Gómez-Jara sostiene que la empresa, alcanzada cierta complejidad organizativa, se autoorganiza de forma penalmente relevante, siendo posible imputarle responsabilidad penal por ello al contar con una libertad organizativa, así como con una participación en la configuración de la sociedad que le permite cuestionar la vigencia de la norma. En consecuencia, la culpabilidad empresarial no precisa abandonar la culpabilidad del acto en lugar de una culpabilidad de autor. Pese al extraordinario esfuerzo conceptual de esta propuesta, se le ha cuestionado llevar a una identidad mediante conceptos tan abstractos que finalmente desdibujan aspectos irrenunciables de la persona individual. ${ }^{32}$

\section{Propuesta de un modelo de atribución de responsabilidad penal a las personas jurídicas por hecho propio}

Desde posiciones generales, se ha dicho que las normas sólo pueden cumplir su función de determinación si se dirigen a sujetos dotados de autoconciencia y libertad, lo que no podría suceder en el caso de las personas jurídicas. ${ }^{33} \mathrm{Al}$ respecto cabe señalar, por un lado, que desde la propia visión motivatoria de la norma penal se ha sostenido que también las personas jurídicas orientan, aunque indirectamente, su actuación en atención a factores externos que inciden económicamente, dentro de los cuales cuentan también las normas penales. ${ }^{34}$ Pero, por otro lado, es igualmente posible construir una teoría de la imputación penal que no se sustente en la norma penal como norma de conducta, sino como norma de sanción, poniendo el centro de la imputación penal no en la prevención futura de delitos a través de procesos motivatorios, sino en el restablecimiento de la vigencia de la norma infringida. ${ }^{35}$ En este caso, la función de restablecer la vigencia de la norma infringida podría conseguirse satisfactoriamente con sanciones penales impuestas a la propia persona jurídica, aunque para ello resulta imprescindible que se le pueda imputar el delito como un hecho suyo, lo que presupone evidentemente la culpabilidad jurídico-penal de la persona jurídica.

\footnotetext{
31 Vid., Gómez-Jara, Carlos: La culpabilidad penal de la empresa (nota 10), pp. 201 ss.

32 Similarmente Schünemann, Bernd: Responsabilidad penal de la empresa (nota 4), pp. 8 y ss.

33 Así, Silva Sánchez, Jesús María: La responsabilidad penal de las personas jurídicas (nota 12), p. 122.

34 Vid., Ehrhardt, Anne: Unternehmensdelinquenz und Unternebmensstrafe: Sanktionen gegen juristische Personen nach deutschem und US-amerikanischem Recht, 1994, pp. 186 ss.

35 Desde una concepción de las normas que abandona su comprensión como directivas psicológicas de conducta y se centra en la norma de contacto que no pretenden una incidencia directa, sino una conducción indirecta de los destinatarios de las normas, Gómez-Jara, Carlos: La culpabilidad penal de la empresa (nota 10), p. 135, sostiene que las personas jurídicas son también destinatarias de normas.
} 
En mi opinión, la culpabilidad de la persona jurídica solamente puede alcanzarse mediante un concepto de culpabilidad analógico. ${ }^{36}$ En la medida que la culpabilidad jurídico-penal se estructura en la individualidad y socialidad de la persona natural, resulta necesario encontrar los equivalentes funcionales de estos aspectos en la persona jurídica. Siguiendo los desarrollos de la teoría de los sistemas, puede llegarse a la conclusión de que el ente colectivo llega a alcanzar una individualidad cuando su complejidad organizativa permite una autorreferencialidad importante de la propia persona jurídica y el desarrollo de intereses societarios ajenos a los de sus órganos, representantes y socios. ${ }^{37}$ Por eso, resulta una posición sumamente interesante, en esta línea, la vinculación de la categoría de la imputabilidad penal en el caso de las personas jurídicas a la complejidad organizativa. ${ }^{38}$

Por otro lado, también es posible el reconocimiento de la socialidad de las personas jurídicas a raíz de su participación individualizada en el marco de su objeto social. La persona jurídica no se presenta en este ámbito en un nivel inferior a la persona natural, sino que actúa con las mismas facultades y capacidades de negociación. ${ }^{39}$ Es titular igualmente del estatus de ciudadano, ${ }^{40}$ lo que otorga a sus actuaciones un sentido jurídico específico y justifica una respuesta social concreta (esto es, responsabilidad). ${ }^{41} \mathrm{La}$ ausencia de derechos

\footnotetext{
${ }^{36} \mathrm{Al}$ respecto, muy esclarecedoras son las palabras de Kaufmann, Arthur: Filosofía del Derecho, 1999, pp. 216 ss.: "Correcta podría ser la concepción que no ve en la persona jurídica ni una persona en el mismo sentido y de la misma estructura real del hombre, ni, tampoco, sólo una ficción que carece de toda realidad, sino una configuración real (...), la cual, en comparación con los hombres, se puede caracterizar como persona en sentido analógico" (cursivas en el original).

37 Vid., Gómez-Jara, Carlos: La culpabilidad penal de la empresa (nota 10), pp. 242 ss. Una cuestión central en este punto constituye la existencia de una autoconciencia o capacidad de reflexión de la persona jurídica a través de su organización. Teubner, KritV, 1987, p. 64, reconoce a la persona jurídica como capaz de autodescribirse y poseer, por tanto, identidad.

38 Vid., con mayor detalle, Gómez-Jara, Carlos: “¿Imputabilidad de las personas jurídicas?”, en AA.VV., Homenaje al Prof. Dr. Gonz̧alo Rodríguez. Mourullo, 2005, pp. 425 ss.

39 Vid., Hurtado Pozo, José: "Responsabilidad penal de la empresa en el Derecho penal suizo", en Moreno Hernández, Moisés (coord.), La ciencia penal en el umbral del siglo XXI, Moreno Hernández (coord.), 2001, p. 462.

40 Vid., en este sentido, la idea del buen ciudadano corporativo del Derecho estadounidense expuesta por Dannecker, Gerhard: "Das Unternehmen als 'good Corporate Citizen' - ein Leitbild der europäischen Rechtsentwicklung?”, en Alwart, Heiner (Hrsg.), Verantwortung und Steuerung von Unternehmen in der Marktwirtschaft, 1998, pp. 6 s.; Weiland, Josef: "Globalisierung und rechtliche Verantwortung. Die Unternehmung als Akteur der Gesellschaft”, en Alwart, Heiner (Hrsg.), Verantwortung und Steuerung von Unternehmen in der Marktwirtschaft, 1998, p. 55; Tiedemann, Klaus: Wirtschaftsstrafrecht. Einführung und Allgemeiner Teil mit wichtigen Rechtstexten, 2004, p. 122, quien reconoce que este concepto ha sido introducido ya en la jurisprudencia penal alemana. El concepto de ciudadano corporativo ha sido utilizado por Gómez-Jara, Carlos: "Autorganización empresarial y autorresponsabilidad empresarial”, Revista Electrónica de Ciencia Penal y Criminología, 2006, para otorgar a las corporaciones la capacidad de culpabilidad penal.

${ }^{41}$ En este sentido, Teubner, Günther: Unternehmenskorporativismus, KritV, 1987, pp. 73 y ss.; Heine, Günther: Die strafrechtliche Verantwortlichkeit (nota 28), pp. 263 ss.; Hirsch, ADPCP, 1993, p. 1109;
} 
García - Esbozo de un modelo de atribución de responsabilidad penal...

políticos atribuidos a la persona jurídica no puede cuestionar en lo absoluto la atribución del estatus de ciudadano, ${ }^{42}$ pues si se aprecia detenidamente la política, podrá constatarse con facilidad el papel relevante que tienen las empresas en las campañas electorales y en las decisiones de gobierno.

Aceptada la posibilidad de que la persona jurídica pueda ser sujeto capaz de una imputación penal culpable, resulta necesario determinar cuál es el injusto imputable a la persona jurídica. Hay una relativamente extendida coincidencia de que el injusto atribuible a la persona jurídica es una organización defectuosa. Pero esta afirmación precisa aclarar si la responsabilidad penal de la persona jurídica se sustentaría en un injusto de organización independiente del injusto de resultado cometido por su representante o administrador. De ser así, la responsabilidad penal de la persona jurídica no necesitaría que alguno de sus miembros haya realizado un injusto de resultado. Esta situación no parece compatible con un sistema penal anclado en los injustos de resultados, ${ }^{43}$ aunque podría cumplirse con esta exigencia estableciendo como condición objetiva de punibilidad la realización de un injusto de resultado por parte de un miembro de la empresa. ${ }^{44}$

Por mi parte, sin embargo, considero que el defecto de organización de la persona jurídica no forma un injusto independiente del injusto de sus órganos o representantes, sino que se trata de una forma de intervención en un hecho común único. Puede incluso que el órgano o representante no sea responsable por la producción del resultado desvalorado, pero sí lo sea la persona jurídica, como sucede en los casos en los que la organización del órgano se muestra individualmente correcta y lo que fracasa es la organización global de la empresa. ${ }^{45}$ En este contexto de ideas, la persona jurídica, como titular de un ámbito de organización, "utiliza" la configuración organizativa de sus órganos y miembros.

Por el contrario, si la prestación del órgano trae consigo además una infracción de sus propias competencias, cabrá perfectamente atribuirle responsabilidad penal junto con la persona jurídica. Pero debe quedar claro que se trata de una responsabilidad penal personal que se sustentaría en sus propios

\footnotetext{
Vogel, Joachim: Wege zu europäsch-einheitliche Regelungen im Allgemeinen Teil des Strafrechts, JZ, 1995, p. 341; Weiland, Josef: "Globalisierung und rechtliche Verantwortung" (nota 40), p. 58.

${ }^{42}$ Vid., esta apreciación, Feijoo Sánchez, Bernardo: Sanciones para empresas por delitos contra el medio ambiente, 2002 , p. 83.

${ }^{43}$ Vid., así, Schünemann, Bernd: "Nuevas tendencias internacionales", en Bernal Cuéllar, Jaime (coord.), XXV Jornadas Internacionales de Derecho Penal, 2003, p. 292; Robles Planas, Ricardo: “¿Delitos de personas jurídicas?”, InDret (344), 2/2006, p. 15.

${ }^{44}$ Críticamente Van Weezel, Alex: "Contra la responsabilidad penal de las personas jurídicas", Politica Criminal, 2010, p. 122.

45 Jakobs, Günther: Derecho Penal, PG, Apdo 29, n.m. 73, nota 128, reconoce la competencia por organización en una organización incluso cuando las personas naturales actuantes no son per se competentes.
} 
ámbitos de organización. ${ }^{46}$ La persona jurídica es titular de una esfera de organización propia y puede, por ello, hacérsele responsable directamente por los defectos de configuración negativos o positivos de su esfera de organización. ${ }^{47}$ No se trata, por tanto, de una infracción de sus órganos o representantes que simplemente se le imputa a la persona jurídica, sino de una infracción propia de la persona jurídica. ${ }^{48} \mathrm{El}$ defecto por organización no es un injusto, sino lo que la hace organizativamente competente por el hecho que defrauda la norma. A su vez, los miembros de la empresa responderán por la competencia que surge de sus propios aportes en la actuación de la empresa.

\section{El modelo de responsabilidad de las personas jurídicas en el Derecho Penal Chileno}

En diciembre de 2009 se promulgó en Chile la Ley Nº 20.393 (DO 02.12.2009) que establece la responsabilidad penal de las personas jurídicas en los delitos de lavado de activos, financiamiento del terrorismo y cohecho. Este paso legislativo que se adelantó al consenso de la doctrina penal chilena ha llevado a la necesidad de discutir el modelo de responsabilidad penal finalmente asumido. Sin embargo, existen algunos autores que niegan que sea posible una responsabilidad penal de las propias personas jurídicas, por lo que ensayan una interpretación del modelo que parte de negar la posibilidad de construir una culpabilidad penal corporativa. Así, por ejemplo, van Weezel sostiene que la interpretación menos lesiva de la actual regulación chilena es aquella que sustenta la responsabilidad penal de la persona jurídica de manera subsidiaria por no haber podido imputarle responsabilidad a una persona individual. ${ }^{49}$ No obstante, la opinión mayoritaria va en la línea de sostener que el modelo de responsabilidad penal de la propia persona jurídica no está configurado como subsidiario, siendo la cuestión a discutir, más bien, si se basa en un hecho ajeno o en un hecho propio.

\section{a) E1 modelo asumido}

Hernández Basualto ha señalado que la Ley de la Responsabilidad Penal de las Personas Jurídicas sigue un modelo mixto que, en rigor, no es más que una variante más o menos morigerada del modelo de responsabilidad derivada, en el sentido de no satisfacerse con una conexión meramente formal entre la entidad y la persona natural responsable y exigir, en cambio, algún tipo de "aporte"

\footnotetext{
${ }^{46}$ Similarmente, Orce, Guillermo: "Responsabilidad penal de las personas jurídicas", en AA.VV., El funcionalismo en Derecho penal, Libro Homenaje al Profesor Günther Jakobs, 2003, p. 385.

47 Vid., Jakobs, Günther: Derecho Penal, PG, Apdo 29, n.m. 73, nota 148; García Cavero, Percy: La responsabilidad penal del administrador de hecho de la empresa: Criterios de imputación, 1999, p. 66.

48 Vid., en este sentido, como acción de la persona jurídica, Teubner, KritV 1987, p. 63; Heine, Günter: Europäische Entwicklungen bei der strafrechtlichen Verantwortlichkeit von Wirtschaftsunternehmen und deren Führungskräften, SchwZStr, 120, 2001, p. 24; Seelmann, Kurt: Punibilidad de la empresa (nota 2), pp. 27 ss.; Zugaldía, José Miguel: “Capacidad de acción” (nota 5), 1994, p. 624.

49 Van Weezel, Alex: “Contra la responsabilidad penal” (nota 44), p. 139.
} 
García - Esbozo de un modelo de atribución de responsabilidad penal...

propiamente organizacional al delito. ${ }^{50}$ Pero en la medida que la responsabilidad penal de la persona natural siga siendo presupuesto de la de la persona jurídica, se tratará sin duda de una responsabilidad derivada. Los delitos por los que la persona jurídica puede ser hecha penalmente responsable deben haber sido cometidos directa e inmediatamente en su interés o para su provecho, por sus dueños, controladores, responsables, ejecutivos principales, representantes o quienes realicen actividades de administración y supervisión.

En relación con la forma en la que se configura la responsabilidad penal de la persona jurídica en la normativa penal chilena, me gustaría postular algunas consideraciones con el mejor ánimo de ofrecer alternativas que se ajusten mejor a una responsabilidad penal propia de los entes corporativos. Creo necesario sostener primeramente que la responsabilidad penal de la persona jurídica es propia y, por lo tanto, se sustenta en un fundamento independiente de la imputación penal a las personas naturales. Sin embargo, la regulación chilena ha convertido los delitos en los que pudiese intervenir una persona jurídica como delitos de intervención necesaria, en que se requiere la intervención responsable de una persona natural además de la intervención de la persona jurídica. Pero queda claro que la competencia jurídico-penal de cada uno se determina de forma independiente, por lo que no hay una responsabilidad de la persona jurídica por el hecho de su órgano o representante. Como se dijo, es perfectamente posible que la persona jurídica pueda responder sin que exista una competencia de algún sujeto individual, pues de su esfera de organización puede salir un riesgo prohibido por el que individualmente nadie resulte responsable. Sin embargo, la actual legislación penal chilena no permite castigar estos casos de "organizada irresponsabilidad", en la medida que requiere necesariamente que también intervenga responsablemente un sujeto individual que actúe en interés del ente colectivo.

La ley penal chilena delimita además el círculo de las personas naturales que pueden cometer los delitos por los que también podría responder la persona jurídica en caso de un defecto de organización. Se trata de los dueños, controladores, responsables, ejecutivos principales, representantes o quienes realicen actividades de administración y supervisión, así como las personas naturales que estén bajo la dirección o supervisión directa de alguno de los sujetos mencionados en el inciso anterior. Precisa que estos sujetos individuales deben de actuar en interés directo e inmediato de la persona jurídica. Este aspecto de la regulación ha dado pie a que se considere que el modelo chileno mezcla aspectos de una responsabilidad por hecho de otro y por hecho propio. Sin embargo, me parece que no es esa la lectura que habría que darle, sino que la ley ha preferido, por razones posiblemente de seguridad jurídica, delimitar expresamente el universo de posibles agentes en el ámbito de organización de una persona jurídica. Está claro que esta delimitación no es restrictiva, ${ }^{51}$ por lo que no apunta únicamente a

\footnotetext{
${ }^{50}$ Hernández, Héctor: "La introducción a la responsabilidad penal” (nota 6), p. 217.

51 Reconoce el carácter extensivo del círculo de posibles sujetos individuales que no se reduce a los cargos directivos, Hernández, Héctor: "La introducción a la responsabilidad penal” (nota 6), p. 220.
} 
los que son alter ego de la persona jurídica, sino a los que en general actúan en su ámbito de organización. Por lo tanto, no se trata de un hecho de conexión, sino de una delimitación (más o menos feliz, ya se verá) de las personas que actúan en el ámbito de organización de la persona jurídica.

Pero con independencia de si es correcta la delimitación del ámbito organizativo de la persona jurídica, el requisito del interés directo e inmediato, sin embargo, sí es un cuerpo extraño que debe modificarse. No sólo por la propia coherencia del modelo de atribución de responsabilidad penal de la persona jurídica, sino, sobre todo, por no corresponderse al sentido de la regulación penal chilena. Por ejemplo: uno de los posibles delitos que puede cometer una persona jurídica es el lavado de activos. Si un banco no desarrolla un programa de prevención del lavado y esto permite que un funcionario suyo proceda a lavar dinero de un cliente sin ser detectado, entonces el banco podrá alegar que, aun cuando no ha cumplido con incorporar un programa de prevención que habría impedido el delito de lavado, no será penalmente responsable, pues el funcionario bancario no actuó en interés suyo (en caso de que el titular de los fondos sólo haya pagado al miembro individual por los actos de lavado), sino del cliente titular de los fondos.

\section{b) Los programas de cumplimiento}

Uno de los aspectos más interesantes de la regulación chilena es la disposición que establece que los deberes de dirección y supervisión se entenderán por cumplidos (y, por lo tanto, no habrá organización defectuosa por la que castigar a la persona jurídica) cuando, con anterioridad a la comisión del delito, la persona jurídica hubiere adoptado e implementado modelos de organización, administración y supervisión para prevenir delitos como el cometido, conforme a lo dispuesto en la propia ley de responsabilidad penal de las personas jurídicas.

Sin entrar en los detalles de cómo tendrían que organizarse los programas de cumplimiento para generar la exoneración de responsabilidad penal a la persona jurídica, me gustaría discutir de manera general y muy brevemente la naturaleza de esta disposición. Podría pensarse que es una causa de exclusión de la punibilidad, de manera tal que, aunque exista un delito, a la persona jurídica no se le podrá punir por ello. Es evidente que difícilmente se puede considerar que los programas de cumplimiento son causas de exclusión de la punibilidad, no sólo porque no son supuestos posteriores al delito, sino porque no responden a una falta de necesidad de pena en el caso concreto, sino a que no podrá sustentarse la defectuosa organización en dichos casos. En realidad con los programas de cumplimiento se estarían estableciendo criterios de determinación del riesgo permitido, de manera tal que si la persona jurídica incorporó programas de prevención adecuados, el riesgo de que, pese a todo, se pueda cometer un delito en el marco de su actuación, se convierte en un riesgo tolerado, pues, de lo contrario, lo que habría que proceder es a suprimir la actividad de la persona jurídica, lo que evidentemente paralizaría la dinámica de la economía y la sociedad moderna. 
García - Esbozo de un modelo de atribución de responsabilidad penal...

La implementación de programas de cumplimiento que permitiría determinar el riesgo permitido en la actuación penalmente relevante de las personas jurídicas, suscita la cuestión de si cabe que una persona jurídica recurra legítimamente a otros mecanismos para controlar adecuadamente los riesgos penales de su actividad, de manera tal que si se constata la comisión de un delito en el marco de su actividad, pueda alegar que tuvo en cuenta mecanismos de control igual de idóneos que los establecidos específicamente en la normativa penal. Se trata claramente de lo que se conoce como la compensación de riesgos, en donde se ha sostenido que si las normas jurídicas disponen la manera de control el riesgo, no es posible reemplazar los mecanismos previstos por otros nuevos igualmente o más efectivos. ${ }^{52} \mathrm{Si}$ una compensación de riesgos tuviese relevancia frente a lo establecido jurídicamente, se pondría en duda la vinculatoriedad de la legislación y se aumentaría el peligro de un desorden en los sectores regulados. No obstante, es de tener en consideración que la ley penal no establece el imperativo de adoptar e implementar un "modelo de prevención" con las características que detalla luego la propia ley, sino que utiliza la frase "podrán adoptar" el modelo previsto, lo que tiene un indudable carácter potestativo. ${ }^{53}$

Otra de las cuestiones generales que deberá esclarecerse es si, pese a no contar la persona jurídica con la adopción e implementación de un programa de cumplimiento, no cabe imputarle objetivamente el resultado, en la medida que un comportamiento alternativo conforme a derecho no habría evitado el resultado producido directamente por el miembro individual de la persona jurídica. Si se sigue la teoría de la evitabilidad, podría negarse, en general, la posibilidad de una imputación objetiva del resultado en estos casos. Por el contrario, si se sigue la teoría del incremento del riesgo, bastará simplemente con señalar que la omisión de incorporar un programa de cumplimiento incrementó el riesgo de comisión del delito, lo que permitiría sustentar la imputación del resultado en una gran cantidad de casos. Por su parte, la teoría del fin de protección de la norma llevaría a sostener que la razón de ser del establecimiento del deber de incorporar en la organización de las personas jurídicas mecanismos de control es impedir la comisión de delitos por parte de sus órganos o representantes, por lo que el incumplimiento de este deber permitirá la imputación del resultado, exceptuando únicamente los casos en los que el delito cometido que se habría impedido no forma parte de aquellos que los programas de cumplimiento pretenden impedir. Como puede verse, a no ser que se asuma la teoría de evitabilidad con la maleabilidad de sus soluciones en función de la conducta hipotética que se tenga en consideración, los casos de comportamientos alternativos a derecho deben

\footnotetext{
52 Vid., en este sentido, Jakobs, Günther: La imputación objetiva en Derecho penal, 1996, pp. 128 s. De una opinión distinta, Frisch, Wolfgang: Comportamiento típico e imputación objetiva del resultado, 2004, p. 108, nota al pie de página 8; Feijoo Sánchez, Bernardo: Imputación objetiva, 2002, pp. 247 ss.

53 Así, también, Hernández, Héctor: "La introducción a la responsabilidad penal" (nota 6), pp. 225 ss.; Van Weezel, Alex: “Contra la responsabilidad penal” (nota 44), pp. 138 ss.
} 
REJ - Revista de Estudios de la Justicia - No 16 - Año 2012

resolverse, manteniendo la imputación del resultado producido directamente por el órgano o miembro de la persona jurídica.

\section{Valoración final}

No hay duda de que el Derecho penal chileno ha dado un paso muy importante en la configuración de un sistema penal moderno que tenga en cuenta los rasgos característicos de la sociedad actual. Pese al apuro y al motor estrictamente político del cambio producido en cuanto a la responsabilidad penal de las personas jurídicas -lo que es sin duda la situación estándar de este tipo de modificaciones-, no puede negársele la gran utilidad que tiene para el cumplimiento de la función asignada al sistema penal. El trabajo recae ahora sobre los tribunales penales que, con ayuda de la rigurosa doctrina penal chilena, deberán precisar las condiciones para imponer legítimamente una sanción penal a una persona jurídica. 
García - Esbozo de un modelo de atribución de responsabilidad penal...

\section{BIBLIOGRAFÍA}

* ACHENBACH, Hans: "Sanciones con las que se pueden castigar a las empresas y a las personas que actúan en su nombre en el Derecho alemán" (trad. Joshi), en Silva Sánchez, Jesús María (drg.), Fundamentos de un sistema europeo de Derecho penal, Barcelona, 1995.

* Alessandri, A. / Foffani, L. / Pedrazzi, C. / Seminara, S. / Spagnolo, G.: Manuale di diritto penale dell'impresa, $2^{\mathrm{a}}$ ed., Bologna, 2000.

* ALWART, Heiner: "Strafrechtliche Haftung des Unternehmens - vom Unternehmenstäter zum Tätersunternehmen”, ZStW 105, 1993.

Zurechnen und Verurteilen, Stuttgart, 1998.

"Unternehmensethik durch Sanktion?", en Alwart, Heiner (Hrsg.), Verantwortung und Steuerung von Unternehmen in der Marktwirtschaft, München, 1998.

* BACIGALUPO, Silvina: La responsabilidad penal de las personas jurídicas, Ed. Hammurabi, Buenos Aires, 2001.

* BACIGALUPO Zapater, Enrique: "Las teorías de la pena y el sujeto del Derecho Penal", en Yacobucci, Guillermo (dr.), Los desafíos del Derecho penal en el siglo XXI, Libro Homenaje al Prof. Günther Jakobs, ARA Editores, Lima, 2005.

* BAJO FERNÁNDEZ, Miguel: "La responsabilidad de las personas jurídicas en el Derecho europeo actual", en CDJ: La responsabilidad penal de las sociedades. Actuación en nombre de otro. Responsabilidad de los consejos de administración. Responsabilidad de los subordinados, VII, Madrid, 1994.

* DANNECKER, Gerhard: "Das Unternehmen als, 'good Corporate Citizen' - ein Leitbild der europäischen Rechtsentwicklung?”, en Alwart, Heiner (Hrsg.), Verantwortung und Steuerung von Unternehmen in der Marktwirtschaft, München, 1998.

Zur Notwendigkeit der Einfübrung kriminalrechtlicher Sanktionen gegen Verbände, GA, 2001.

* EHRHARDT, Anne: Unternebmensdelinquen₹ und Unternebmensstrafe: Sanktionen gegen juristische Personen nach deutschem und US-amerikanischem Recht, Berlin, 1994.

* FEIJOO SÁNCHEZ, Bernardo: Sanciones para empresas por delitos contra el medio ambiente, Editorial Civitas, Madrid, 2002.

Imputación objetiva en Derecho Penal, Grijley, Lima, 2002.

* FRISCH, Wolfgang: Comportamiento típico e imputación objetiva del resultado (trad. Cuello/Serrano), Marcial Pons, Madrid, 2004.

* García CAVERO, Percy: Derecho penal económico, Parte general, Grijley, $2^{a}$ ed., Lima, 2007.

La responsabilidad penal del administrador de hecho de la empresa: Criterios de imputación, J.M. Bosch Editor, Barcelona, 1999.

* GÓMEZ-JARA DÍEZ, Carlos: “¿Imputabilidad de las personas jurídicas?”, en Bajo Fernández, Miguel / Jorge Barreiro, Agustín / Suárez González, Carlos (eds.), Homenaje al Prof. Dr. Gonzalo Rodríguez Mourullo, Editorial Civitas, Madrid, 2005.

La culpabilidad penal de la empresa, Marcial Pons, Madrid, 2005.

"Autorganización empresarial y autorresponsabilidad empresarial: Hacia una verdadera responsabilidad penal de las personas jurídicas”, en Revista Electrónica de Ciencia Penaly Criminología, Nº 2006.

* HEINE, Günther: Die strafrechtliche Verantwortlichkeit von Unternebmen, von individuellen Feblverbalten zu kollektiven Feblenwicklungen, insbesondere bei Grossrisiken, Nomos Verlag, Baden-Baden, 1995.

"Plädoyer für ein Verbandsstrafrecht als 'zweite Spur'”, en Alwart, Heiner (Hrsg.), Individuelle Verantwortung und Steuerung von Unternebmen in der Marketwirtschaft, München, 1998. "Europäische Entwicklungen bei der strafrechtlichen Verantwortlichkeit von Wirtschaftsunternehmen und deren Führungskräften”, SchwZStr 120, 2001. 
REJ - Revista de Estudios de la Justicia - No 16 - Año 2012

* HERNÁNDEZ Basualto, Héctor: "La introducción de la responsabilidad penal de las personas jurídicas en Chile", Política Criminal, Vol. 5, No 9, Centro de Estudios de Derecho Penal Universidad de Talca, 2010.

* HURTAdo Pozo, José: "Responsabilidad penal de la empresa en el Derecho penal suizo", en Moreno Hernández, Moisés (coord.), La ciencia penal en el umbral del siglo XXI, Col. Guadalupe Inn, 2001.

* JAKOBS, Günther: La imputación objetiva en Derecho penal (trad. Cancio Meliá), Madrid, 1996.

“¿Punibilidad de las personas jurídicas?” (trad. Suárez González), en García Cavero, Percy (coord.), La responsabilidad penal de las personas jurídicas, órganos y representantes, Mendoza, 2004.

Derecho Penal, PG, Apdo 29, n.m. 73, nota 128 / 148.

* KAUFMANN, Arthur: Filosofía del Derecho (trad. Villar Borda), Universidad Externado de Colombia, Bogotá, 1999.

* KREMNITZER, Mordechai /Ghanayim, Khalid: Die Strafbarkeit von Unternebmen, ZStW 113, 2001.

* LAMPE, Ennst-Joachim: La dogmática jurídico-penal entre la ontología social y el funcionalismo, Edit. Jurídica Grijley, Lima, 2003.

* ORCE, Guillermo: "Responsabilidad penal de las personas jurídicas", en El funcionalismo en Derecho Penal, Libro Homenaje al Profesor Günther Jakobs, Universidad Externado de Colombia, Bogotá D.C., 2003.

* ROBLES Planas, Ricardo: “¿Delitos de personas jurídicas?”, InDret 2/2006 (344), www.indret.com.

* SCHÜNEMANN, Bernd: Unternehmenskriminalität und Strafrecht, Köln-Berlin. BonnMünchen: Heymann, 1979.

"La punibilidad de las personas jurídicas desde la perspectiva europea" (trad. Peñaranda Ramos/Pérez Manzano), en AA.VV., Hacia un Derecho penal económico europeo. Jornadas en honor del Prof. Klaus Tiedemann, BOE, Madrid, 1995.

"Nuevas tendencias internacionales en la responsabilidad penal de personas jurídicas y empresas", en Cuéllar Bernal, Jaime (coord.), XXV Jornadas Internacionales de Derecho Penal, Universidad Externado de Colombia, Bogotá, 2003.

Responsabilidad penal de la empresa y sus órganos directivos en la Unión Europea (trad. Sacher), conferencia dictada en el Seminario "Constitución Europea y Derecho Penal Económico”, dirigida por el Prof. Bajo Fernández, Universidad Autónoma de Madrid, 2006.

* SEELMANN, Kurt: "Punibilidad de la empresa: causas, paradojas y consecuencias" (trad. García Cavero), en García Cavero, Percy (coord.), La responsabilidad penal de las personas jurídicas, órganos y representantes, Mendoza, 2004.

* SILVA Sánchez, Jesús María: "La responsabilidad penal de la empresa y de sus órganos en Derecho español", en del mismo, Fundamentos de un sistema europeo del Derecho penal, J.M. Bosch, Barcelona, 1995.

"La responsabilidad penal de las personas jurídicas y las consecuencias accesorias del artículo 129 del Código Penal Español”, en García Cavero, Percy (coord.), La responsabilidad penal de las personas jurídicas, órganos y representantes, Mendoza, 2004.

* TIEDEMANN, Klaus: "Die "Bebußung" von Unternehmen nach dem 2. Gesetz zur Bekämpfung der Wirtschaftskriminalität”, NJW, 1988. 2004.

Wirtschaftsstrafrecht. Einführung und Allgemeiner Teil mit wichtigen Rechtstexten, Köln,

* TEUBNER, Günther: Unternehmenskorporativismus, KritV, 1987.

* VAN WEEZEL, Alex: "Contra la responsabilidad penal de las personas jurídicas", Política criminal, Vol. 5, Nº 9, Centro de Estudios de Derecho Penal Universidad de Talca, 2010. 
García - Esbozo de un modelo de atribución de responsabilidad penal...

* VOGEL, Joachim: Wege zu europäisch-einheitliche Regelungen im Allgemeinen Teil des Strafrechts, JZ, 1995.

* WEILAND, Josef: "Globalisierung und rechtliche Verantwortung. Die Unternehmung als Akteur der Gesellschaft", en Alwart, Heiner (Hrsg.), Verantwortung und Steuerung von Unternebmen in der Marktwirtschaft, München, 1998.

* ZUGALDÍA Espinar, José Miguel: Capacidad de acción y capacidad de culpabilidad de las personas jurídicas, CPC N 53, 1994.

* ZÚNIGA RODRÍGUEZ, Laura: Bases para un modelo de imputación de responsabilidad penal a las personas jurídicas, El Aranzadi, $2^{a}$ ed., Pamplona, 2003. 